\title{
Numerical Investigation on the Influence of Hot Streak Temperature Ratio in a High-Pressure Stage of Vaneless Counter-Rotating Turbine
}

\author{
Zhao Qingjun, ${ }^{1,2}$ Wang Huishe, ${ }^{1}$ Zhao Xiaolu, ${ }^{1}$ and Xu Jianzhong ${ }^{1}$ \\ ${ }^{1}$ Institute of Engineering Thermophysics, Chinese Academy of Sciences, P.O. Box 2706, Beijing 100080, China \\ ${ }^{2}$ Graduate School of the Chinese Academy of Sciences, P.O. Box 2706, Beijing 100080, China
}

Received 17 July 2006; Revised 29 November 2006; Accepted 30 November 2006

Recommended by Eddie Y.-K. Ng

The results of recent studies have shown that combustor exit temperature distortion can cause excessive heat load of high-pressure turbine (HPT) rotor blades. The heating of HPT rotor blades can lead to thermal fatigue and degrade turbine performance. In order to explore the influence of hot streak temperature ratio on the temperature distributions of HPT airfoil surface, threedimensional multiblade row unsteady Navier-Stokes simulations have been performed in a vaneless counter-rotating turbine (VCRT). The hot streak temperature ratios from 1.0 (without hot streak) to 2.4 were used in these numerical simulations, including 1.0, 1.2, 1.6, 2.0, and 2.4 temperature ratios. The hot streak is circular in shape with a diameter equal to $25 \%$ of the span. The center of the hot streak is located at $50 \%$ of span and $0 \%$ of pitch (the leading edge of the HPT stator vane). The predicted results show that the hot streak is relatively unaffected as it migrates through the HPT stator. The hot streak mixes with the vane wake and convects towards the pressure surface (PS) of the HPT rotor when it moves over the vane surface of the HPT stator. The heat load of the HPT rotor increases with the increase of the hot streak temperature ratio. The existence of the inlet temperature distortion induces a thin layer of cooler air in the HPT rotor, which separates the PS of the HPT rotor from the hotter fluid. The numerical results also indicating the migration characteristics of the hot streak in the HPT rotor are predominated by the combined effects of secondary flow and buoyancy. The combined effects that induce the high-temperature fluid migrate towards the hub on the HPT rotor. The effect of the secondary flow on the hotter fluid increases as the hot streak temperature ratio is increased. The influence of buoyancy is directly proportional to the hot streak temperature ratio. The predicted results show that the increase of the hot streak temperature ratio trends to increase the relative Mach number at the HPT rotor outlet, and decrease the relative flow angle from $25 \%$ to $75 \%$ span at the HPT rotor outlet. In the other region of the HPT outlet, the relative flow angle increases when the hot streak temperature ratio is increased. The predicted results also indicate that the isentropic efficiency of the VCRT decreases with the increase of the hot streak temperature ratio.

Copyright ( 2007 Zhao Qingjun et al. This is an open access article distributed under the Creative Commons Attribution License, which permits unrestricted use, distribution, and reproduction in any medium, provided the original work is properly cited.

\section{INTRODUCTION}

Vanless counter-rotating turbine (VCRT), which is composed of a highly loaded single-stage HPT coupled with a vanless counter-rotating LPT, is used to increase significantly thrust-to-weight ratio of propulsion system while improving reliability and reducing costs (Keith et al. [1]; Haldeman et al. [2]; Weaver et al. [3]). From 1950s, the counter-rotating turbine has been carefully investigated (Wintucky and Stewart [4]; Louis [5]; Ji et al. [6]; Wang et al. [7]). Cai et al. (see [8]) did some basic analyses on counter-rotating turbine and gave a thorough classification about it. Ji et al. (see [6]) did a preliminary theoretical analysis about the efficiency of counter-rotating turbine. The results showed that the SWR and the HPT loading are the critical factors for the counterrotating turbine. In the research of Ji et al. (see [9]), the results indicated that increasing the relative flow angle and Mach number at the HPT exit was also an effective way to provide an appropriate SWR for the VCRT, and it also made one-stage vaneless counter-rotating LP turbine become utility.

Experimental data taken from gas turbine combustors indicate that the flow exiting the combustor can contain both circumferential and radial temperature gradients. The phenomenon is known as hot streaks. The hot streaks arise from the combination of the combustor core flow with the 
combustor bypass and combustor surface cooling flows. In turbine, the hot streaks convect through the vanes and interact with the rotor blades. The existence of the hot streaks causes local hot spots on the blade surfaces, leads to heat fatigue of blade, and reduces the blade life.

An earlier research on streamline pattern showed theoretically that inflow temperature gradients would not alter the streamline pattern in vanes as long as the inflow total pressure was uniform (Munk and Prim [10]). However, the following research on the secondary flow of rotating system, which was performed by Lakshminarayana and Horlock (see [11]), indicated that inflow temperature nonuniformities could lead to secondary flow in the rotating blade rows. Butler et al. (see [12]) carried out an experimental investigation on hot streak migration using the large scale rotating rig (LSRR), which was often used in hot streaks investigations. They also found that the temperature gradients could not alter the flow within the turbine stator but to have significant impact on the flow field of rotor blade rows when the total pressure in the distortion was uniform. Their conclusion had been verified by some other experimental and numerical investigations (Rai and Dring [13]; Roback and Dring [14]; Dorney et al. [15]; Dorney and Davis [16], Dorney [17]). The experimental and numerical results, which were obtained by Butler et al. (see [12]), Sharma et al. (see [18]), Roback and Dring (see [14]), showed that hot streaks caused hotter gas to accumulate on the rotor blade pressure surfaces and colder gas to accumulate on the rotor blade suction surfaces. However, the numerical results of Gundy-Burlet and Dorney (see [19]) indicated that the migration patterns of hot streaks were directly related to the position of the hot streak in relation to the first-stage stator. When the hot streak impinged on the LE of the first-stage stator, the hot gases were convected with the stator wake and migrated to the suction surface (SS) of the first-stage rotor. On the contrary, the hot gases migrated to the PS of the first-stage rotor when the hot streak was located in the midpassage of the first-stage stator vanes. In addition to secondary flow and circumferentially relative location effects, Shang and Epstein (see [20]) showed that the migration of the hot streak was also affected by the buoyancy, which tended to drive the hot streak towards the hub.

The experimental facilities most often used in hot streak investigations include the large scale rotating rig (LSRR) (Butler et al. [12]; Roback and Dring [14]; Dring et al. [21]; Sharma et al. [22]), NASA warm core turbine test rig (WCTTR) (Whitney et al. [23]; Schwab et al. [24]; Stabe et al. [25]), and MIT blowdown turbine test rig (BTTR) (Guenette [26]; Sujudi [27]; Shang [28]). The LSRR experiments were performed at low speed, but blade surface temperature $\left(\mathrm{CO}_{2}\right.$ concentrations) may be measured. In the WCTTR experiments, blade surface temperature could not be measured, but it was a high-speed rig. Compared LSRR and WCTTR, BTTR experiments not only were performed at high speed, but also blade surface temperature could be measured. Shang et al. (see [29]) performed hot streak experiments in the BTTR in order to investigate the effects of hot streak migration on blade surface temperature at high speed.
On the influence of hot streak temperature ratio, some researchers have performed some numerical investigations. The predicted results were compared with the corresponding experimental data. In the LSRR turbine geometry, several two- and three-dimensional simulations have been performed for a hot streak temperature ratio of 1.2 (Rai and Dring [13]; Dorney et al. [15]; Dorney and Davis [16]; Dorney et al. [30]; Mathur et al. [31]). The numerical simulations qualitatively predicted the temperature redistribution patterns within the turbine rotor, but the quantitative levels of the surface temperature distributions showed only fair agreement with the experimental data. Takahashi and Ni (see $[32,33])$ performed two- and three-dimensional hot streak migration simulations for LSRR turbine using temperature ratios of 1.5 and 2.0. The results showed that temperature ratio played an important role in the accurate prediction of turbine blade temperature distributions. Krouthen and Giles (see [34]) performed a two-dimensional hot streak simulation for the LSRR with a temperature ratio of 2.0. Their results exhibited closer agreement with experimental data than results obtained at a temperature ratio of 1.2. Dorney (see [17]) carried out two-dimensional unsteady hot streak simulations for the LSRR turbine at temperature ratios of 1.5, 2.0 , and 2.5, respectively. The predicted results indicated that under certain flow conditions, a thin layer of cooler air separates the PS of the turbine rotor from the hottest fluid. The source of the cooler fluid layer was traced to intermitting flow separation, which became more frequent as the hot streak temperature ratio was increased.

On other different geometries, some researchers also have performed hot streak simulations. Harasgama (see [35]) and Weigand and Harasgama (see [36]) performed hot streak simulations on a high-speed turbine rotor at a temperature ratio of 1.2. Kirtley et al. (see [37]) conducted threedimensional viscous hot streak simulations on the space shuttle main engine fuel turbine at a temperature ratio of approximately 1.2. Saxer and Giles [38] and Saxer and Felici [39] performed three-dimensional simulations of hot streak migration in transonic turbine stages at temperature ratios of 1.2 and 1.97, respectively. Dorney and Schwab (see [40]) studied radial temperature profile redistribution in the single-stage turbine with a temperature ratio of 1.06 .

This paper is to study the effects of the hot streak temperature ratio on the HPT airfoil surface temperature distributions in the VCRT. Hot streak temperature ratios of between 1.0 and 2.4 , including $1.0,1.2,1.6,2.0$, and 2.4 temperature ratios, are used in the numerical simulations of flow through the VCRT.

\section{NUMERICAL ALGORITHM}

NUMECA software systems are employed to study the problem, and the structured grid is produced by NUMECA AutoGrid.

The numerical method used by NUMECA code is described in detail in its user manual (see [41]). Here only a brief description of the main features will be reported. 
The governing equations in NUMECA are the timedependent, three-dimensional Reynolds-averaged NavierStokes equations. The solver of NUMECA is FINE/Turbo and it is based on a cell centered finite volume approach, associated with a central space discretization scheme together with an explicit four-stage Runge-Kutta time integration method.

Residual smoothing, local time stepping, and multigridding are employed to speed up convergence to the steady-state solution. A dual time stepping method (Arnone and Pacciani [42], Jameson, [43]) is used to perform time accurate calculations.

This analysis uses $\mathrm{O}$ - and $\mathrm{H}$-type zonal grids to discretize the flow field and facilitate relative motion of the rotating components. The O-grids are body-fitted to the surfaces of the airfoils and the H-grids are used to discretize the reminder of the flow field. They are used to properly resolve the viscous flow in the blade passage and easily apply the choice turbulence model.

The cell width along the walls must always be carefully chosen. Indeed, the quality of the flow solution will often depend upon the fine capture of the flow phenomena inside the boundary layers which develop along the solid walls. Therefore, the cell width along the walls must be adapted to the numerical treatment of the flow in the immediate vicinity of walls. The numerical treatment of walls is mainly driven by the turbulence model.

The relation between $y^{+}$and the first cell width, $y$, can be estimated by means of the Blasius equation (see [41]), expressed as follows for turbulent flows:

$$
y=6\left(\frac{V_{\mathrm{ref}}}{v}\right)^{(-7 / 8)}\left(\frac{L_{\mathrm{ref}}}{2}\right)^{(1 / 8)} y^{+} .
$$

When $y^{+}$values are less than that of NUMECA recommendation value, the computational mesh density is determined by increasing cell counts in the streamwise and bladeto-blade direction, and radial direction until the steady inlet mass flow, outlet mass flow, efficiency, and pressure ratio do not change significantly.

Inflow and outflow boundaries are treated via a onedimensional characteristic scheme. Inlet flow angle, total pressure, and temperature are imposed at the inlet. At the outlet static pressure is assigned.

Various turbulence models have been included in the solver for the closure of the governing equations. The widely used approach based on one transport equation (Spalart and Allmaras [44]) has been selected in this paper. The SpalartAllmaras model has become quite popular in the last years because of its robustness and its ability to treat complex flows. The main advantage of the Spalart-Allmaras model when compared to the one of Baldwin-Lomax is that the turbulent eddy viscosity field is always continuous. Its advantage over the $k-\varepsilon$ model is mainly its robustness and the lower additional CPU and memory usage. When the SpalartAllmaras model is selected, the kinematic turbulent viscosity should be specified in the inlet boundary condition. In this paper, it is $0.0001 \mathrm{~m}^{2} / \mathrm{s}$.

The time step limitations arising from the turbulent source terms are accounted for in the model so that compu-
TABLE 1: Grid dimensions ( $i$-azimuthal direction, $j$-spanwise direction, $k$-streamwise direction).

\begin{tabular}{l|crc}
\hline Row & $i \times j \times k$ & Nodes & Blocks \\
\hline HPT-inlet & $33 \times 49 \times 25$ & 40,425 & 1 \\
HPT-stator & $25 \times 49 \times 185$ & 226,625 & 1 \\
HPT-rotor & $17 \times 49 \times 241$ & 200,753 & 1 \\
LPT-rotor & $17 \times 49 \times 193$ & 160,769 & 1 \\
LPT-outlet & $41 \times 49 \times 25$ & 50,225 & 1 \\
\hline
\end{tabular}

tations can be performed with the maximum allowable CFL number without penalizing numerical efficiency.

\section{VANELESS COUNTER-ROTATING TURBINE}

In order to increase the work capability of the LP turbine of the VCRT, the outflow of the HPT rotor must have a high relative Mach number $(\sim 1.5)$ and high relative flow angle $\left(\sim 70^{\circ}\right)$ (Ji et al. [6]). Former research showed that the upper bound of outflow relative Mach number of a good convergent turbine cascade passage was $1.2 \sim 1.3$, and a good performance of a convergent-divergent turbine cascade passage could only be obtained when the outflow relative Mach number was beyond $1.3 \sim 1.4$. Therefore, the HPT rotor studied in this paper is designed to convergent-divergent nozzle.

The turbine under investigation is a modern, highly loaded single-stage HPT coupled with a vaneless counterrotating LPT, recently designed and studied under the Chinese National 973 programs concerning the development of highly loaded components for aeronautic gas turbine (G1999022305). Both of the two stages feature high expansion ratios and work in transonic regimes. The HP stage is particularly critical, being characterized by a pitch averaged relative Mach number exceeding the value of 1.4 at almost all the HPT rotor outlets. The performance of the VCRT has been researched in literature, see Wang et al. [45].

The airfoil counts in the steady and unsteady models are reduced from the actual count 36/36/36 for the HPT stator, HPT rotor, and LPT rotor, respectively, to $1 / 1 / 1$ for computational efficiency. And no tip clearance of the rotor is modeled. That results in a CFD model with about 0.68 million grid points (Table 1) employing a sheared " $\mathrm{H}-\mathrm{O}-\mathrm{H}$ " mesh, and solution time of less than one week in a $3.0 \mathrm{GHz}$ one-IntelCPU computer. Typical $y^{+}$values of less than 15 are used at the boundaries according to the turbulence model (Spalart and Allmaras [44]), NUMECA recommendation value, and the computer capability.

Figure 1 shows the grids used for the VCRT study. With an " $\mathrm{H}-\mathrm{O}-\mathrm{H}$ "-type structure, it is relatively easy to control the uniformity and density of the grid before the blade passage to prevent an excessive smearing of the incoming wakes, and reduce the mesh skewness. Based on past experiences on the steady three-dimensional viscous analyses of the VCRT (Zhao et al. [46]), the selected grid size (Table 1) is considered to be adequate for the purposes of the study. 


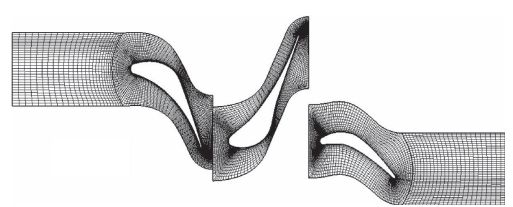

S1 section (midspan)

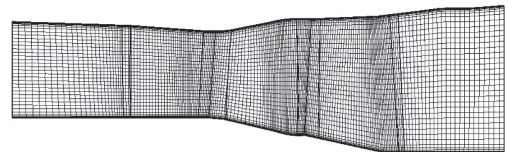

S2 section (midpitch)

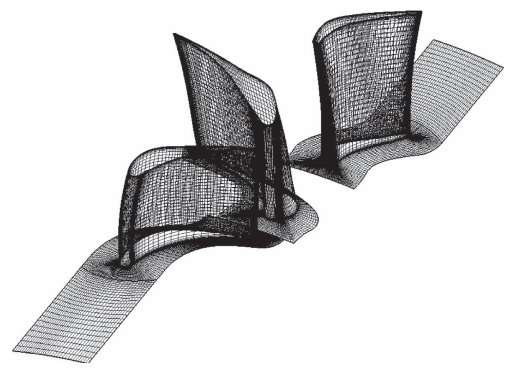

Three-dimensional grid topology

Figure 1: $\mathrm{H}-\mathrm{O}-\mathrm{H}$ grid topology for the VCRT.

TABLE 2: Flow conditions in the NASA test turbine.

\begin{tabular}{l|c}
\hline Inlet total temperature $(\mathrm{K})$ & 672.2 \\
Inlet total pressure $(\mathrm{Pa})$ & $3.103 \times 10^{5}$ \\
Mass flow $(\mathrm{kg} / \mathrm{s})$ & 6.13 \\
Specific work $(\mathrm{J} / \mathrm{kg})$ & $1.299 \times 10^{5}$ \\
Rotational speed $(\mathrm{RPM})$ & 11373 \\
Total pressure ratio & 2.36 \\
Load factor & 1.675 \\
Flow coefficient & 0.449 \\
\hline
\end{tabular}

\section{VALIDATION OF NUMERICAL CODE}

In order to validate the predicted accuracy of the numerical code, a three-dimensional multistage unsteady Navier-Stokes simulation with inlet radial hot streak has been performed in a test turbine. Then the time-averaged numerical data are compared with the available experimental data. The test turbine is a 0.767 scale rig modeling the first stage of a two-stage core turbine designed for a modern high bypass ratio engine. The vane has a constant section, and was designed for a constant exit flow angle of $75^{\circ}$ from axial. The rotor inlet was designed to accept the vane exit flow with either zero or slight negative incidence. The rotor outlet is a free-vortex design. Both vane and blade axial chords are constant radially. The experimental turbine has 26 vane airfoils and 48 rotor airfoils. It was tested in the NASA Lewis Research Center's WCTTR (Stabe et al. [25]; Dorney et al. [47]). The test conditions for the turbine are shown in Table 2.

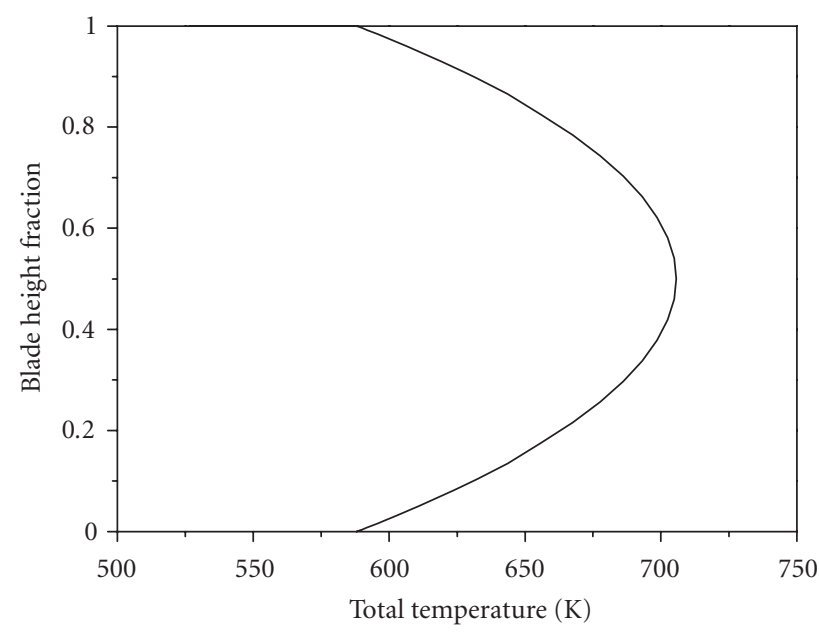

FIgURE 2: Turbine inlet radial temperature profile.

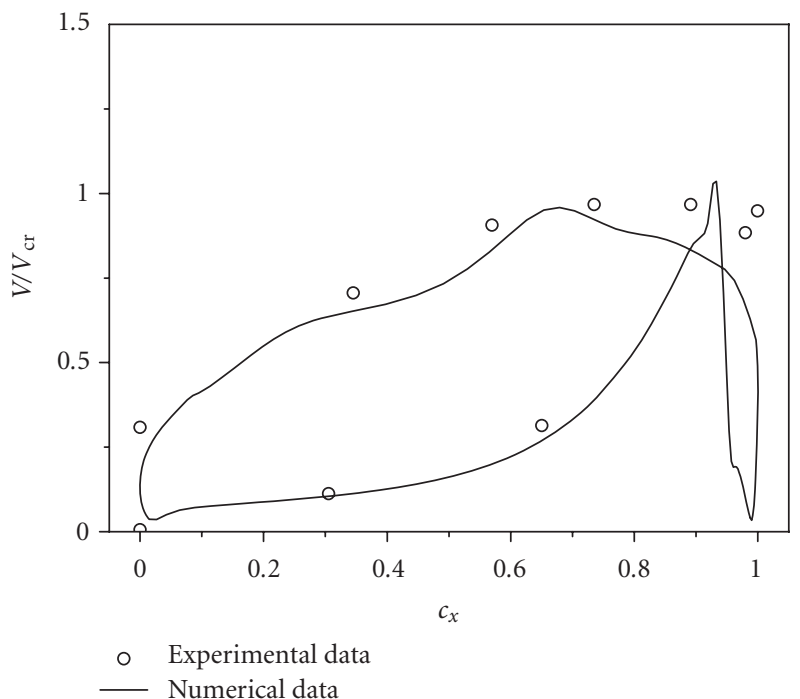

Figure 3: Critical velocity ratio at the hub of the vane.

The inlet radial temperature profile in the experiment was produced using the CERTS (combustor exit radial temperature simulator) inlet which injected cool air through circumferential slots in the hub and tip endwalls upstream of the vane. Figure 2 shows the inlet radial temperature distribution. The ratio of the maximum total temperature to the average total temperature is approximately 1.05 , and the ratio of maximum to minimum total temperature is approximately 1.20 at the turbine inlet.

For reducing the cost of the calculation, the number of vanes in the first row is decreased to 24 and the size of the vane is increased by a factor of 26/24 to maintain the same blockage. So, a 1-vane/2-rotor airfoil count ratio is used in the unsteady numerical simulation.

Figures 3 to 5 show comparisons between the predicted and experimental time-averaged critical velocity ratio distributions at the hub, midspan, and tip of the vane. The predicted data are very close to the experimental data, except for 


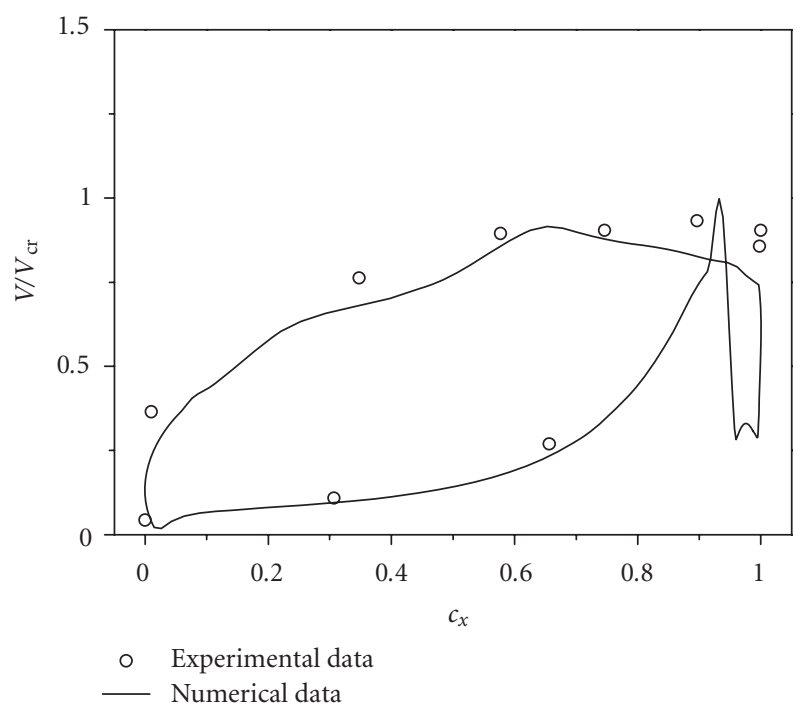

Figure 4: Critical velocity ratio at the midspan of the vane.

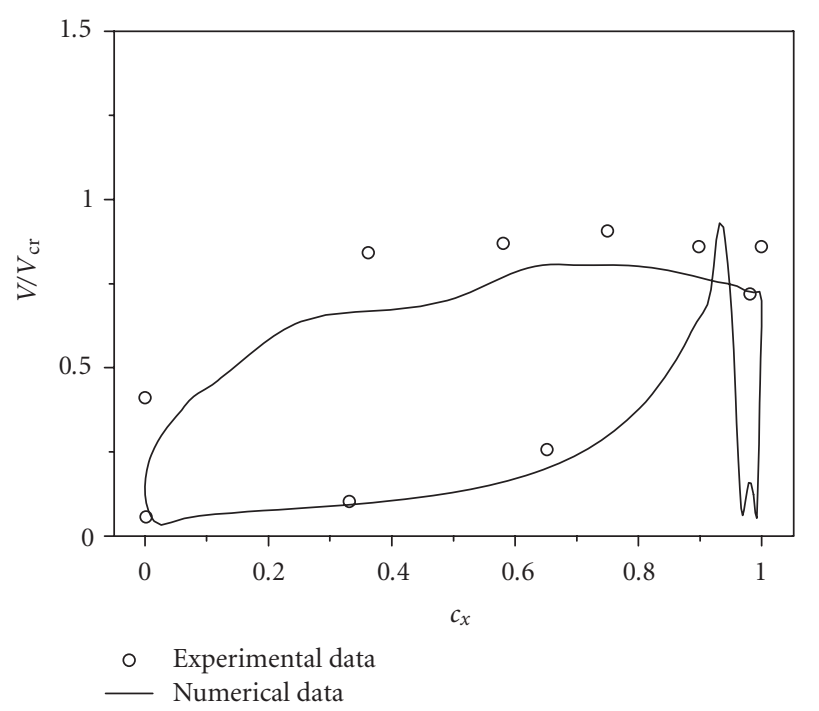

FIgURE 5: Critical velocity ratio at the tip of the vane.

near the TE region of the vane and the SS at the tip of the vane.

Figure 6 illustrates the predicted and experimental total pressure distributions at the outlet of the turbine. There is good agreement between the predicted and experimental results.

Figure 7 shows the predicted and experimental total temperature distributions at the outlet of the turbine. The predicted values show close agreement with the experimental values from hub to $70 \%$ span. The discrepancies near the tip region are due to the differences in the experimental $(1.2 \%)$ and numerical (0\%) tip clearances.

The above-mentioned results indicate that the predicted accuracy of the numerical code is acceptable in this investigation.

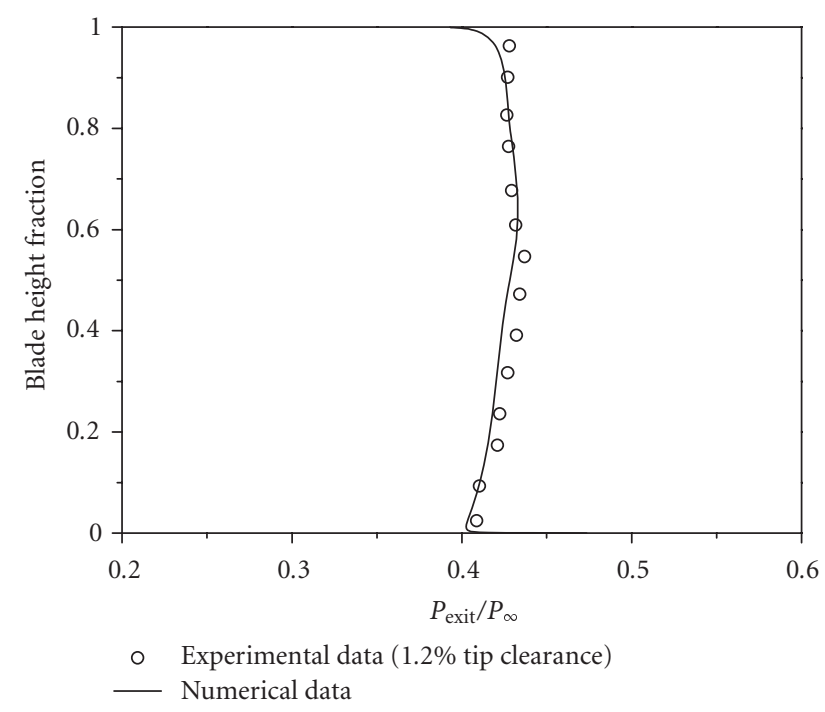

Figure 6: Total pressure distribution at the outlet of the turbine.

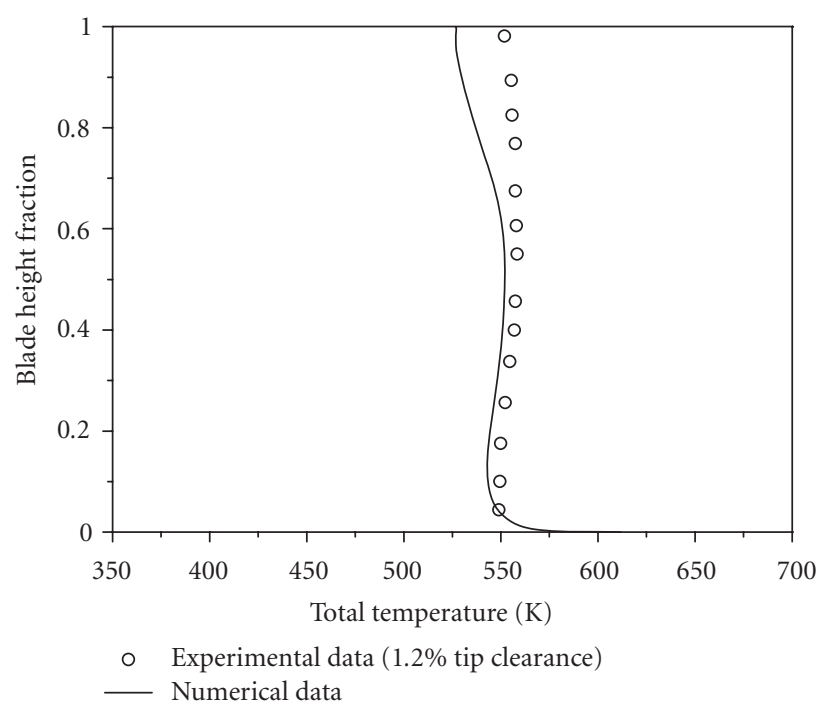

FIGURE 7: Total temperature distribution at the outlet of the turbine.

\section{HOT STREAK PROFILES}

In this paper, hot streak temperature ratios from 1.0 (without hot streak) to 2.4 are selected in numerical simulations, including 1.0, 1.2, 1.6, 2.0, and 2.4 temperature ratios. Each hot streak is circular in shape with a diameter equal to $25 \%$ of the span. The hot streak center is located at $50 \%$ of span and $0 \%$ of pitch. Figure 8 shows the inlet hot streak profiles.

\section{NUMERICAL RESULTS}

A series of numerical experiments simulating hot streak migration through the VCRT has been performed using a three-dimensional unsteady Navier-Stokes procedure called FINE/Turbo. In these numerical simulations, the hot streak temperature ratios of between 1.0 and 2.4, including 1.0, 1.2, 1.6, 2.0, and 2.4, have been selected. 


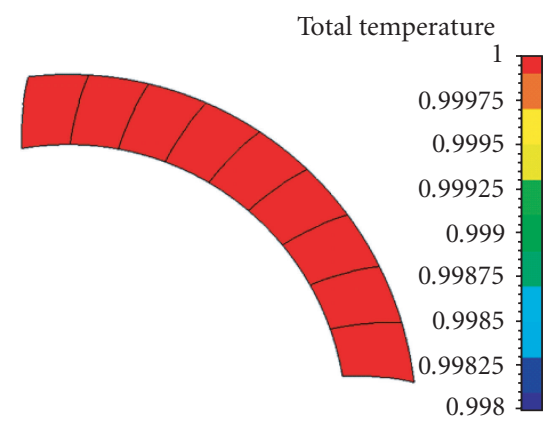

Case 1: $T_{\mathrm{hs}} / T_{\infty}=1$

(a)

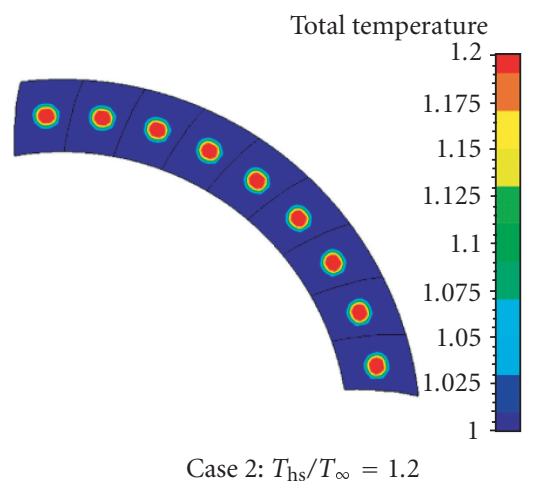

(b)

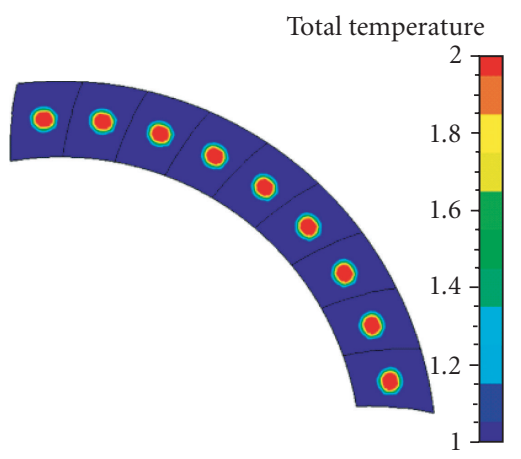

Case 4: $T_{\mathrm{hs}} / T_{\infty}=2$

(d)

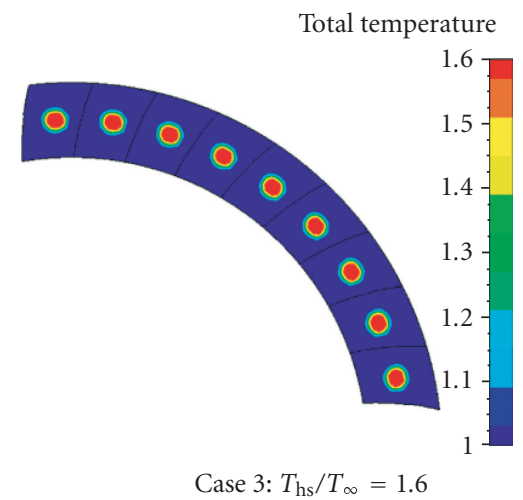

(c)

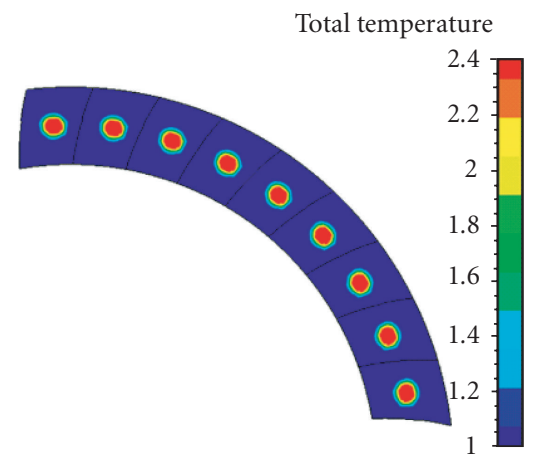

Case 5: $T_{\mathrm{hs}} / T_{\infty}=2.4$

(e)

Figure 8: Hot streak profiles.

Figure 9 illustrates the migration paths of the hot streaks on the midspan of the HPT, which are highlighted using static temperature contours at one instant in time. The result of the simulation without hot streak (i.e., $T_{\mathrm{hs}} / T_{\infty}=1.0$ ) shows that the separation of cold and hot fluids has not been observed at the inlet of the HPT rotor. The temperature distribution is almost uniform at the inlet of the HPT rotor. However, the results of these simulations with hot streak show that the separation of cold and hot fluids occurs at the inlet of the HPT rotor. The hot streak is relatively unaffected as it migrates through the HPT stator. The hot streak mixes with the vane wake and convects towards the PS of the HPT rotor. The hot streak accumulates on the PS of the HPT rotor. Then the heat load of the HPT rotor is increased. A few of hotter fluid can also round the LE of the HPT rotor and migrate to the SS of the HPT rotor. However, the hotter fluid cannot accumulate on the SS. Finally, it will migrate towards the PS with the other hotter fluid. The migration paths of the hot streaks also indicate that the hotter fluid more easily migrates to the PS of the HPT rotor for a higher hot streak temperature ratio.

Table 3 contains the time-averaged hot streak center static temperature at the inlet of the HPT stator and rotor and the temperature variations between the inlet of the HPT 


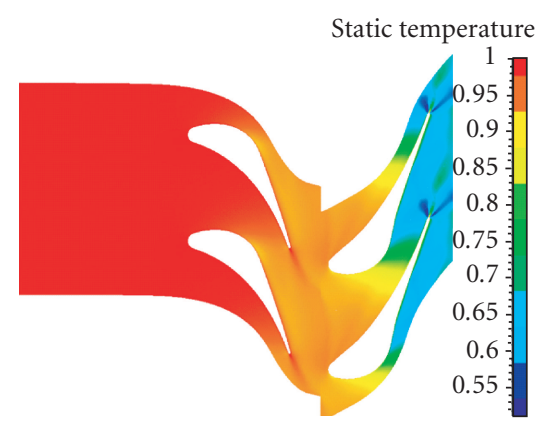

Case 1: $T_{\mathrm{hs}} / T_{\infty}=1$

(a)

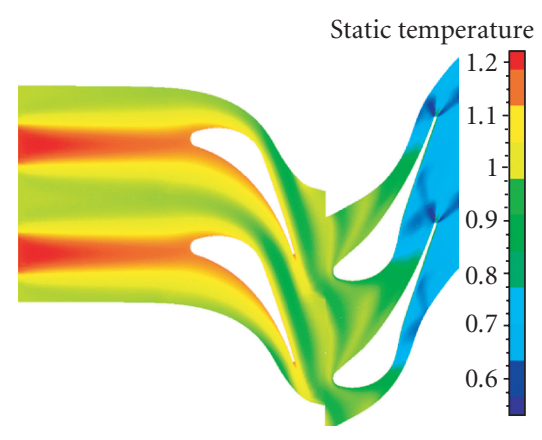

Case 2: $T_{\mathrm{hs}} / T_{\infty}=1.2$

(b)

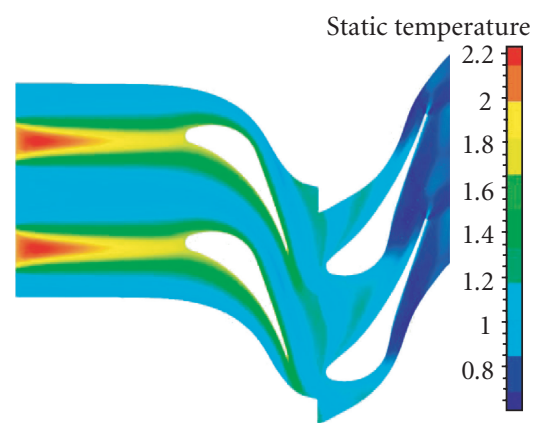

Case 4: $T_{\mathrm{hs}} / T_{\infty}=2$

(d)

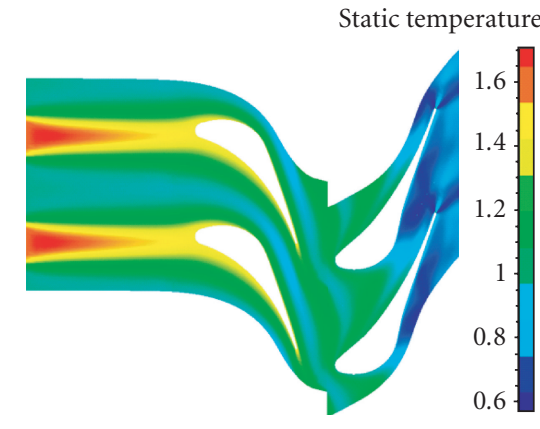

Case 3: $T_{\mathrm{hs}} / T_{\infty}=1.6$

(c)

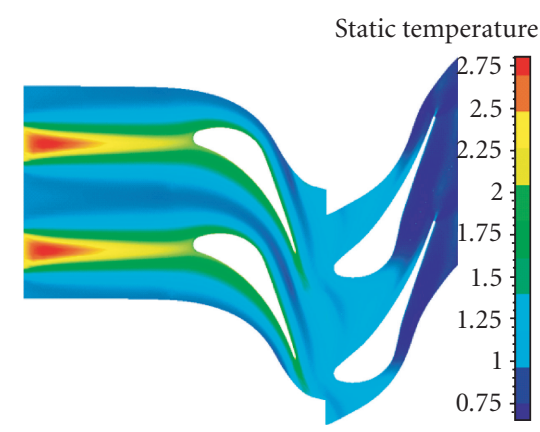

Case 5: $T_{\mathrm{hs}} / T_{\infty}=2.4$

(e)

FIGURE 9: Temperature contours at the midspan of the HPT.

TABLE 3: Hot streak center temperature and temperature variation.

\begin{tabular}{l|llc}
\hline$T_{\mathrm{hs}} / T_{\infty}$ & \multicolumn{1}{|c}{$t_{1}$} & \multicolumn{1}{c}{$t_{2}$} & $\Delta t\left(t_{1}-t_{2}\right)$ \\
\hline$T_{\mathrm{hs}} / T_{\infty}=1.0$ & 0.998 & 0.941 & 0.057 \\
$T_{\mathrm{hs}} / T_{\infty}=1.2$ & 1.15 & 0.983 & 0.167 \\
$T_{\mathrm{hs}} / T_{\infty}=1.6$ & 1.45 & 1.05 & 0.4 \\
$T_{\mathrm{hs}} / T_{\infty}=2.0$ & 1.75 & 1.12 & 0.63 \\
$T_{\mathrm{hs}} / T_{\infty}=2.4$ & 2.06 & 1.18 & 0.88 \\
\hline
\end{tabular}

stator and the inlet of the HPT rotor for different temperature ratios at the midspan section of the HPT. The results indicate that the hot streak center temperature will be dissi- pated somewhat before reaching the inlet of the HPT rotor. The temperature variation increases with the increase of the hot streak temperature ratio. It shows that the increase of the hot streak temperature ratio tends to increase the dissipated degree of the peak temperature.

Figure 10 illustrates time-averaged temperature contours at the midspan of the HPT rotor passage for hot streak temperature ratios of $1.2,1.6,2.0$, and 2.4 , respectively. For all four temperature ratios, the hot streak fluid accumulates on the PS of the HPT rotor. However, the hottest fluid is not located on the PS of the HPT rotor. A thin layer of cooler fluid lies between the PS of the HPT rotor and the hottest fluid. The phenomenon was also reported in $[17,30]$. The results 


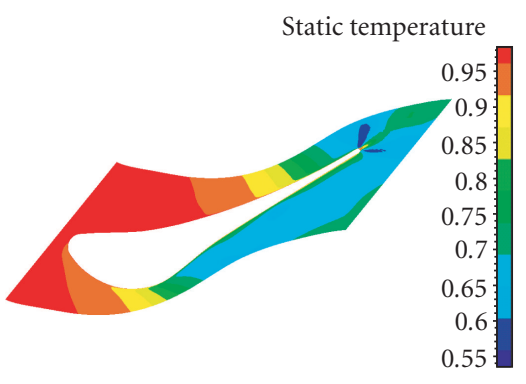

Panorama of PS temperature contour

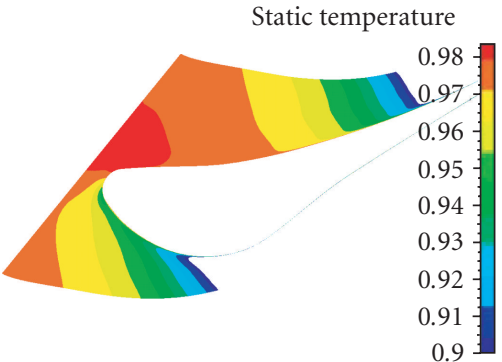

Close-up of PS temperature contour

Case 2: $T_{\mathrm{hs}} / T_{\infty}=1.2$

(a)

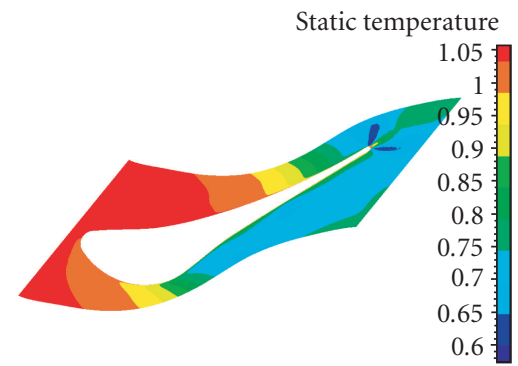

Panorama of PS temperature contour

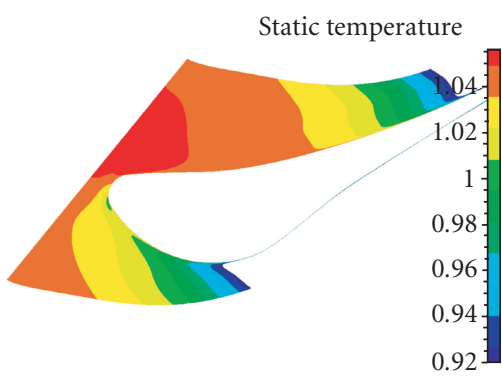

Close-up of PS temperature contour

Case 3: $T_{\mathrm{hs}} / T_{\infty}=1.6$

(b)

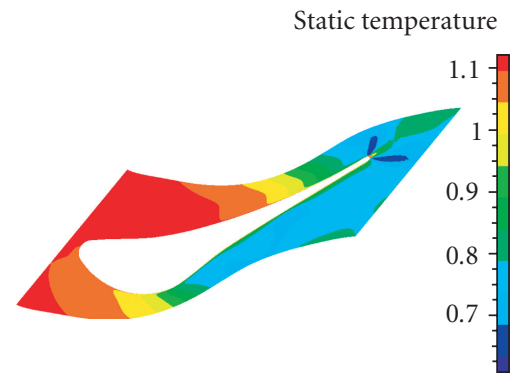

Panorama of PS temperature contour

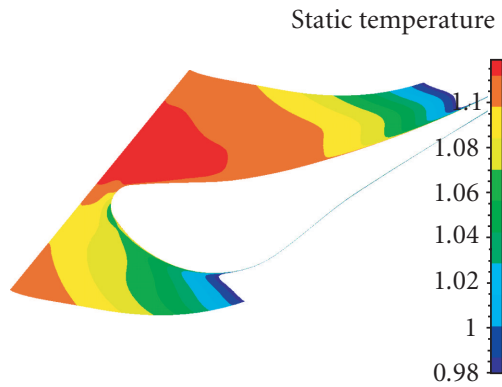

Close-up of PS temperature contour

Case 4: $T_{\mathrm{hs}} / T_{\infty}=2$

(c)

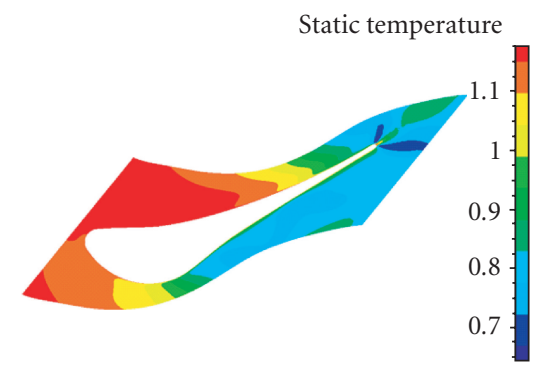

Panorama of PS temperature contour

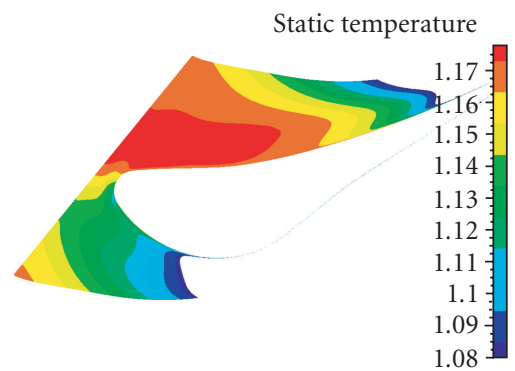

Close-up of PS temperature contour

Case 5: $T_{\mathrm{hs}} / T_{\infty}=2.4$

(d)

FIGURE 10: Time-averaged temperature contours at the midspan of the HPT rotor. 


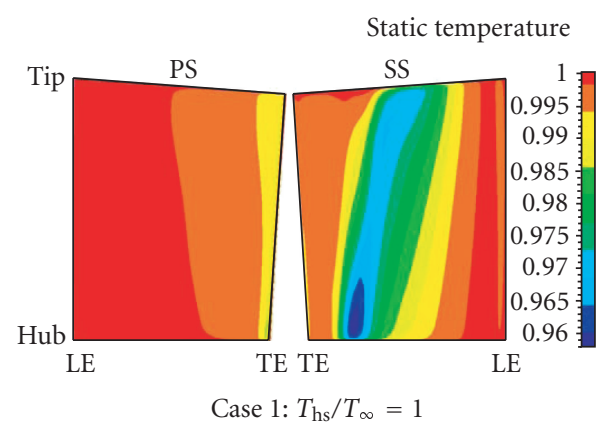

(a)

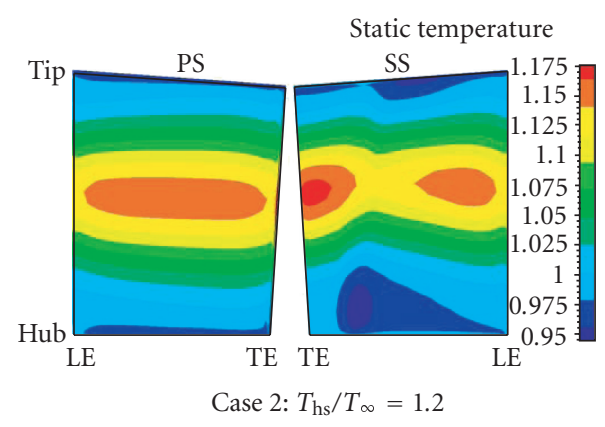

(b)

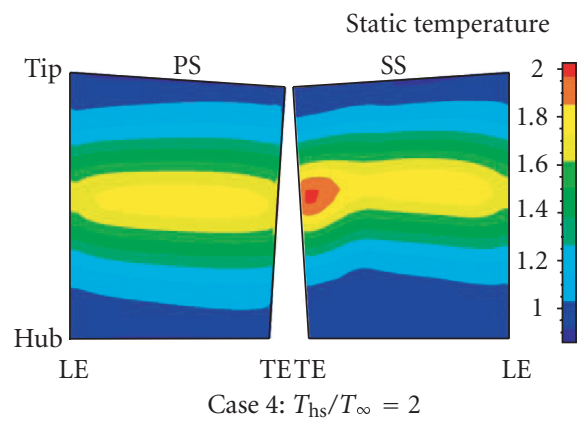

(d)

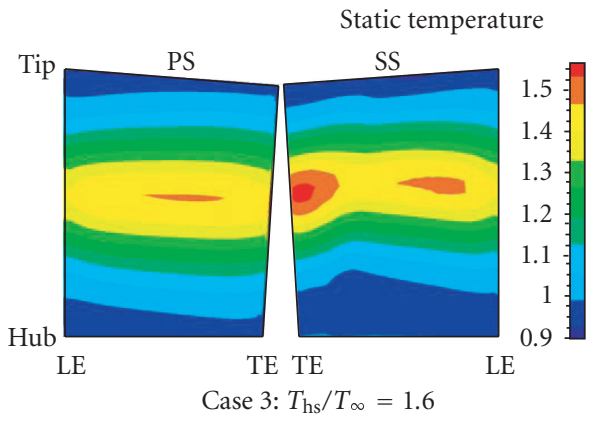

(c)

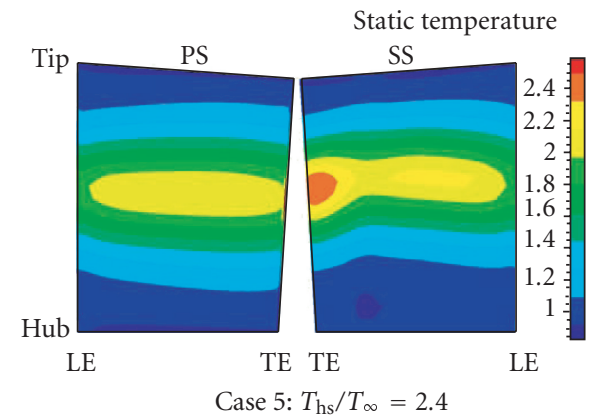

(e)

Figure 11: Time-averaged static temperature contours on the HPT stator.

in Figure 10 also show that the increase of the hot streak temperature ratio tends to enlarge the distribution range of the cooler fluid layer.

Figure 11 illustrates the static temperature contours on the HPT stator for different temperature ratios. The radial temperature distribution is uniform for case $1, T_{\mathrm{hs}} / T_{\infty}=1.0$. The hot streaks induce nonuniform temperature distributions along the spanwise of the HPT stator for other inlet temperature ratios. However, the hot streaks are relatively unaffected when they migrate through the HPT stator. The temperature redistributions, which are induced by the secondary flow, have not occurred in the stator vanes for all the temperature ratios. After going through the stator vanes, the hot streaks will mix with the vane wakes and convect towards the PS of the HPT rotor.
In former research (Zhao et al. [48]), the conclusion that the migration characteristics of the hot streak in the HPT rotor are predominated by the combined effects of secondary flow and buoyancy has been obtained. Figure 12 shows the static temperature contours on the HPT rotor for different temperature ratios. The temperature distribution is uniform on the whole HPT rotor for the case $1, T_{\mathrm{hs}} / T_{\infty}=1.0$. The result shows that uniform inlet temperature tends to induce uniform temperature distribution on the HPT rotor. For other temperature ratios, the temperature redistributions have occurred on the HPT rotor. The secondary flow in the rotor passages drives the hotter fluid towards the hub and tip on the rotor PS. However, the secondary flow makes the hotter fluid migrate towards the midspan on the rotor SS. The influence of the buoyancy drives the high-temperature 


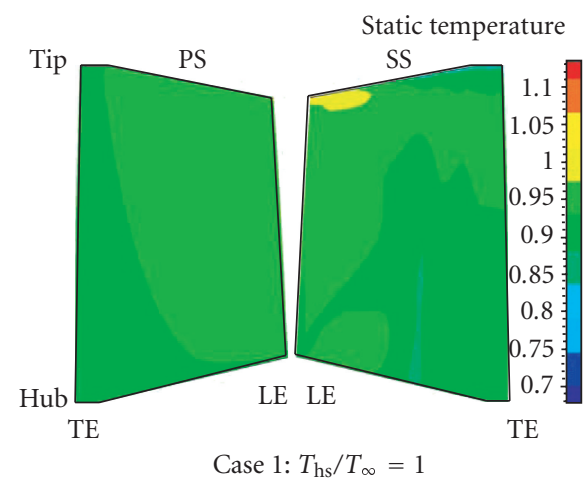

(a)

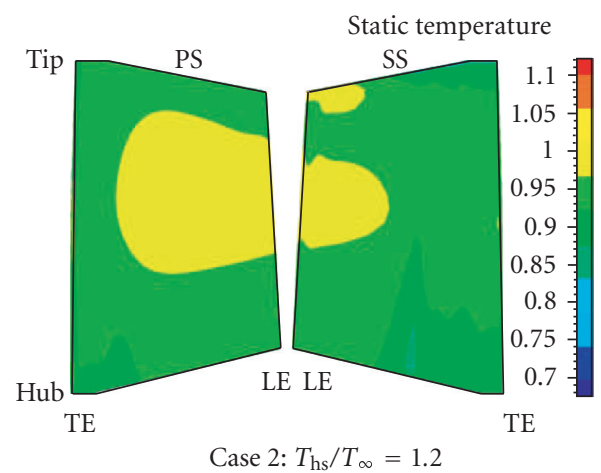

(b)

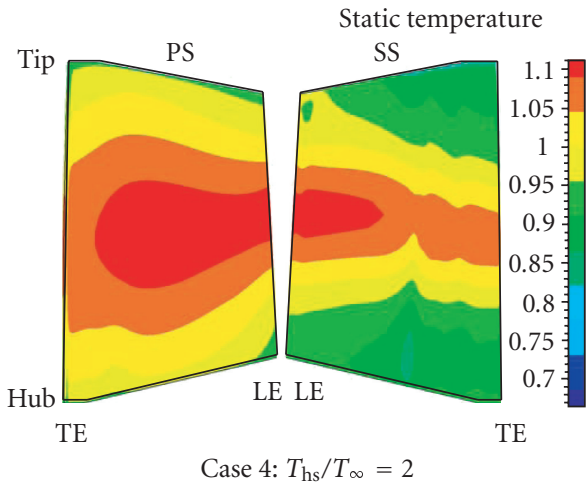

(d)

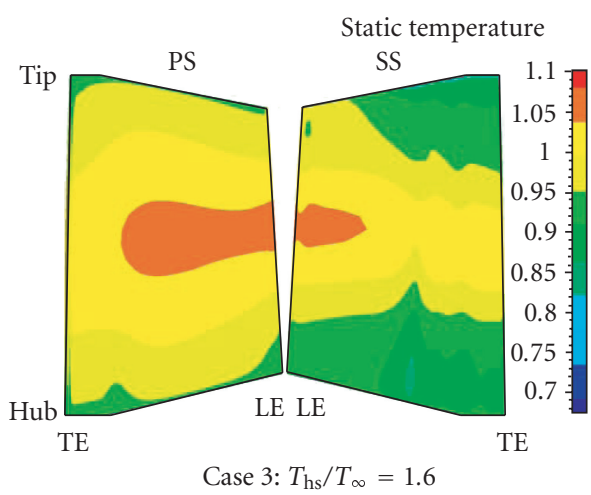

(c)

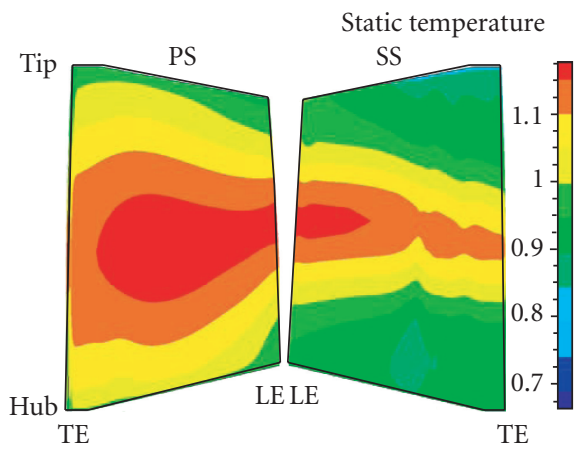

Case 5: $T_{\mathrm{hs}} / T_{\infty}=2.4$

(e)

FIgURE 12: Time-averaged static temperature contours on the HPT rotor.

fluid towards the hub on the rotor PS and SS. The combined effects induce the high-temperature fluid migrate towards the hub on the HPT rotor (see Figure 12).

The results in Figure 12 also show that the effects of secondary flow and buoyancy on the hotter fluid increase with the increase of the hot streak temperature ratio. The effect of buoyancy on the migration of the hot streak can be explained by using the simple radial equilibrium theory. The radial equilibrium is a balance between the pressure force and the centrifugal force along the radial direction. The expression is described as follows in the stationary frame (Dixon
[49]):

$$
\frac{d p}{d r}=\rho \frac{V_{\theta}^{2}}{r} .
$$

In the rotational frame, the radial equilibrium equation is obtained:

$$
\frac{d p}{d r}=\rho \frac{U^{2}}{r}+\rho \frac{2 U W_{\theta}}{r}+\rho \frac{W_{\theta}^{2}}{r} .
$$

In the HPT rotor, the radial pressure field is established by the free-stream flow. So, the radial pressure gradient of the 
hot streak fluid is similar to the free-stream flow (see (4)),

$$
\frac{d p_{\infty}}{d r}=\rho_{\infty} \frac{U^{2}}{r}+\rho_{\infty} \frac{2 U W_{\theta, \infty}}{r}+\rho_{\infty} \frac{W_{\theta, \infty}^{2}}{r}=\frac{d p_{\mathrm{hs}}}{d r} .
$$

According to Newton's second law of motion, the force balance is established for the hot streak fluid in the HPT rotor (see (5)),

$$
\frac{d p_{\mathrm{hs}}}{d r}-\left(\rho_{\mathrm{hs}} \frac{U^{2}}{r}+\rho_{\mathrm{hs}} \frac{2 U W_{\theta, \mathrm{hs}}}{r}+\rho_{\infty} \frac{W_{\theta, \mathrm{hs}}^{2}}{r}\right)=\rho_{\mathrm{hs}} \frac{d^{2} \delta}{d t^{2}} .
$$

And because the tangential velocity in the relative frame is much smaller than the rotor wheel speed at near the region of the HPT rotor surface, (4) and (5) are simplified as

$$
\begin{gathered}
\frac{d p_{\infty}}{d r}=\rho_{\infty} \frac{U^{2}}{r}=\frac{d p_{\mathrm{hs}}}{d r}, \\
\frac{d p_{\mathrm{hs}}}{d r}-\rho_{\mathrm{hs}} \frac{U^{2}}{r}=\rho_{\mathrm{hs}} \frac{d^{2} \delta}{d t^{2}} .
\end{gathered}
$$

Combining (6), then

$$
\frac{U^{2}}{r}\left(\frac{\rho_{\infty}}{\rho_{\mathrm{hs}}}-1\right)=\frac{d^{2} \delta}{d t^{2}} .
$$

Considering that

$$
\begin{aligned}
& \frac{\rho_{\infty}}{\rho_{\mathrm{hs}}}=\frac{t_{\mathrm{hs}}}{t_{\infty}}, \\
& W_{x}=\frac{d x}{d t},
\end{aligned}
$$

(7) is changed as

$$
\frac{d^{2} \delta}{d x^{2}}=\frac{1}{r} \frac{U^{2}}{W_{x}^{2}}\left(\frac{t_{\mathrm{hs}}}{t_{\infty}}-1\right)=\frac{1}{r}\left(\frac{t_{\mathrm{hs}}}{t_{\infty}}-1\right) \frac{1}{\phi^{2}} .
$$

And since $\left(t_{\mathrm{hs}} / t_{\infty}\right)_{\text {rotor }} \propto\left(T_{\mathrm{hs}} / T_{\infty}\right)_{\text {inlet }},(9)$ is written as

$$
\frac{d^{2} \delta}{d x^{2}}=\frac{1}{r}\left(k\left(\frac{T_{\mathrm{hs}}}{T_{\infty}}\right)_{\text {inlet }}-1\right) \frac{1}{\phi^{2}},
$$

where $k$ is a constant.

Equation (10) offers an evaluation criterion on the buoyancy effect from physical mechanism. The buoyancy effect is proportional to the inlet hot streak temperature ratio and depends on the square of flow coefficient with inverse proportion. Using (10), the buoyancy effect of hot streak fluid can be well estimated.

Figures 13 and 14 show the time- and pitch-averaged relative Mach number distributions and relative flow angle distributions at the HPT rotor outlet, respectively. The relative Mach number increases with the increase of the hot streak temperature ratio along the whole outlet. When the hot streak temperature ratio increases, the relative flow angle decreases from $25 \%$ to $75 \%$ span at the HPT rotor outlet. In the other region of the HPT rotor outlet (from the hub to $25 \%$ span and from $75 \%$ span to the tip), the relative flow angle increases as the hot streak temperature ratio increases.

Figure 15 illustrates the effect of the hot streak temperature ratio on the total-total efficiency of the VCRT. The totaltotal efficiency of the VCRT decreases with the increase of the hot streak temperature ratio.

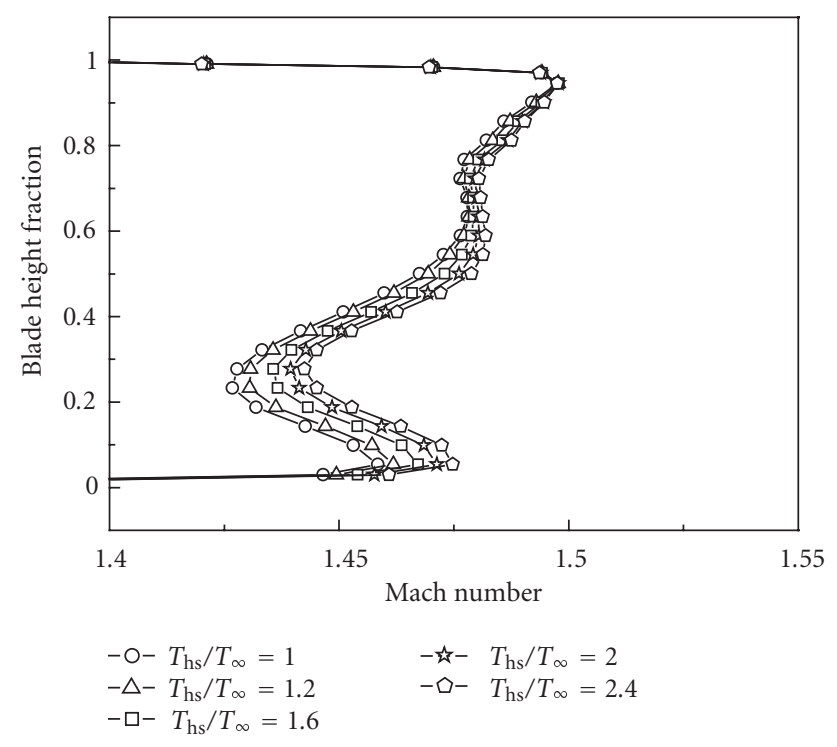

Figure 13: Time- and pitch-averaged Mach number distributions at the outlet of the HPT rotor.

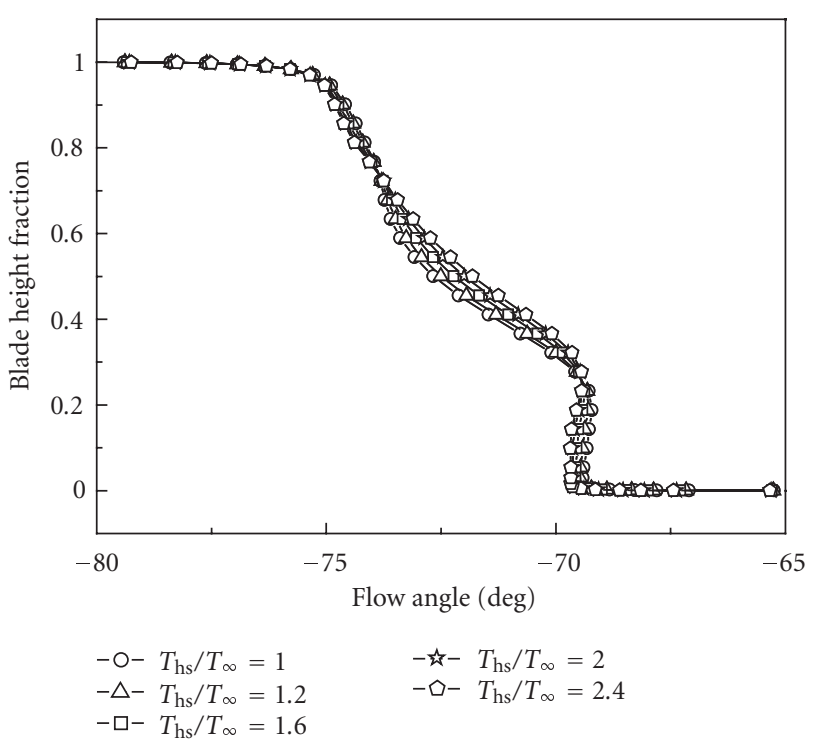

FIGURE 14: Time- and pitch-averaged flow angle distributions at the outlet of the HPT rotor.

\section{CONCLUSIONS}

This paper is to study the effects of the hot streak temperature ratio on the HPT temperature distributions in the VCRT. The major conclusions can be summarized as follows.

(1) The hot streak is relatively unaffected as it migrates through the HPT stator.

(2) The hot streak mixes with the vane wake and convects towards the PS of the HPT rotor when it moves over the vane surface of the HPT stator. The heat load of the HPT rotor increases with the increase of the hot streak temperature ratio. 


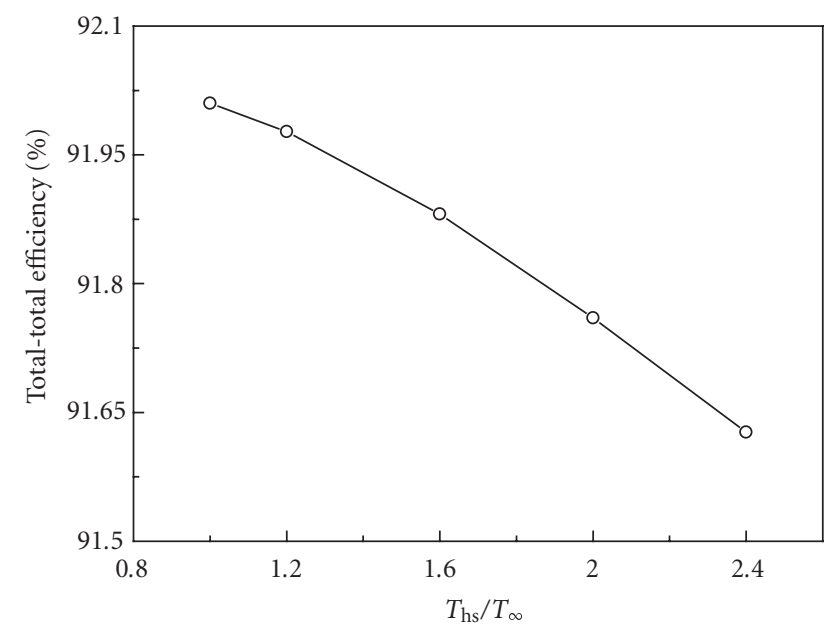

FIgURE 15: The influence of hot streak temperature ratio on the total-total efficiency of the VCRT.

(3) The existence of the inlet temperature distortion induces a thin layer of cooler air in the HPT rotor, which separates the PS of the HPT rotor from the hotter fluid.

(4) The migration characteristics of the hot streak in the HPT rotor are predominated by the combined effects of secondary flow and buoyancy. The combined effects induce the high-temperature fluid migrate towards the hub on the HPT rotor. The effects of secondary flow and buoyancy on the hotter fluid increase with the increase of the hot streak temperature ratio.

(5) The increase of the hot streak temperature ratio trends to increase the relative Mach number at the HPT rotor outlet, and decrease the relative flow angle from $25 \%$ to $75 \%$ span at the HPT rotor outlet. In the other region of the HPT outlet (from the hub to $25 \%$ span and from $75 \%$ span to the tip), the relative flow angle increases as the hot streak temperature ratio increases.

(6) The isentropic efficiency of the VCRT decreases when the hot streak temperature ratio increases.

\section{NOMENCLATURE}

VCRT: $1+1 / 2$ counter-rotating turbine (vaneless counterrotating turbine)

HP: $\quad$ High pressure

LP: Low pressure

HPT: High-pressure turbine

LPT: Low-pressure turbine

SWR: The ratio of specific work of the HPT to that of LPT

PS: $\quad$ Pressure surface

SS: $\quad$ Suction surface

LE: Leading edge
TE: Trailing edge

T: Total temperature

$t$ : Static temperature or time

$P$ : Total pressure

$p:$ Static pressure

$\rho:$ Density

$\delta$ : Radial displacement of hot streak fluid

$c$ : Nondimensional chord

$x$ : Axial displacement

$r$ : Radius

$U:$ Rotor wheel speed

$V$ : Absolute velocity

$W$ : Relative velocity

$\phi$ : Flow coefficient

\section{SUBSCRIPTS}

hs: Hot streak

$\infty$ : Free stream quantity

cr: Critical value

inlet: Turbine inlet

exit: Turbine exit

1: $\quad$ HPT stator inlet quantity

2: $\quad$ HPT rotor inlet quantity

$\theta: \quad$ Tangential direction

$x$ : Axial direction

\section{ACKNOWLEDGMENT}

This work has been partly funded by Chinese National 973 Program (G1999022305), fiscal year 2004.

\section{REFERENCES}

[1] B. D. Keith, D. K. Basu, and C. Stevens, "Aerodynamic test results of Controlled Pressure Ratio Engine (COPE) dual spool air turbine rotating rig," ASME Paper 2000-GT-0632, ASME, Munich, Germany, 2000.

[2] C. W. Haldeman, M. G. Dunn, R. S. Abhari, P. D. Johnson, and X. A. Montesdeoca, "Experimental and computational investigation of the time-averaged and time-resolved pressure loading on a vaneless counter-rotating turbine," ASME Paper 2000-GT-0445, ASME, Munich, Germany, 2000.

[3] M. M. Weaver, S. R. Manwaring, R. S. Abhari, M. J. Salay, K. K. Frey, and N. Heidegger, "Forcing function measurements and predictions of a transonic vaneless counter rotating turbine," ASME Paper 2000-GT-0375, ASME, Munich, Germany, 2000.

[4] W. T. Wintucky and W. L. Stewart, "Analysis of two-stage counter-rotating turbine efficiencies in terms of work and speed requirements," Tech. Rep. NACA RM E57L05, NASA, Washington, DC, USA, 1957.

[5] J. F. Louis, "Axial flow contra-rotating turbines," ASME Paper 85-GT-218, ASME, Houston, Tex, USA, 1985.

[6] L. C. Ji, X. B. Quan, L. Wei, and J. Z. Xu, "A vaneless counterrotating turbine design towards limit of specific work ratio," ISABE Paper 2001-1062, ISABE, Bangalore, India, 2001.

[7] H. Wang, Q. Zhao, X. Zhao, and J. Xu, "Unsteady numerical simulation of shock systems in vaneless counter-rotating turbine," ASME Paper 2005-GT-68212, ASME, Reno-Tahoe, Nev, USA, 2005. 
[8] R. Cai, W. Wu, and G. Fang, "Basic analysis of counter-rotating turbines," ASME Paper 90-GT-108, ASME, Brussels, Belgium, 1990.

[9] L. C. Ji, L. Xiang, H. B. Huang, and J. Z. Xu, "The revelations from the research about the vaneless counter-rotating turbine," ISABE Paper 2003-1040, ISABE, Cleveland, Ohio, USA, 2003.

[10] M. Munk and R. C. Prim, "On the multiplicity of steady gas flows having the same streamline pattern," Proceedings of the National Academy of Sciences of the United States of America, vol. 33, no. 5, pp. 137-141, 1947.

[11] B. Lakshminarayana and J. H. Horlock, "Generalized expressions for secondary vorticity using intrinsic co-ordinates," Journal of Fluid Mechanics, vol. 59, no. 1, pp. 97-115, 1973.

[12] T. L. Butler, O. P. Sharma, H. D. Joslyn, and R. P. Dring, "Redistribution of an inlet temperature distortion in an axial flow turbine stage," Journal of Propulsion and Power, vol. 5, no. 1, pp. 64-71, 1989.

[13] M. M. Rai and R. P. Dring, "Navier-Stokes analyses of the redistribution of inlet temperature distortions in a turbine," Journal of Propulsion and Power, vol. 6, no. 3, pp. 276-282, 1990.

[14] R. J. Roback and R. P. Dring, "Hot streaks and phantom cooling in a turbine rotor passage: part 1-separate effects," ASME Paper 92-GT-75, ASME, Cologne, Germany, 1992.

[15] D. J. Dorney, R. L. Davis, D. E. Edwards, and N. K. Madavan, "Unsteady analysis of hot streak migration in a turbine stage," Journal of Propulsion and Power, vol. 8, no. 2, pp. 520-529, 1992.

[16] D. J. Dorney and R. L. Davis, "Numerical simulation of turbine 'hot spot' alleviation using film cooling," Journal of Propulsion and Power, vol. 9, no. 3, pp. 329-336, 1993.

[17] D. J. Dorney, "Numerical investigation of hot streak temperature ratio scaling effects," AIAA Paper 96-0619, AIAA, Reno, Nev, USA, 1996.

[18] O. P. Sharma, G. F. Pickett, and R. H. Ni, "Assessment of unsteady flows in turbines," ASME Paper 90-GT-150, ASME, Brussels, Belgium, 1990.

[19] K. L. Gundy-Burlet and D. J. Dorney, "Three-dimensional simulations of hot streak clocking in a 1-1/2 stage turbine," AIAA Paper 96-2791, AIAA, Bellevue, Wash, USA, 1996.

[20] T. Shang and A. H. Epstein, "Analysis of hot streak effects on turbine rotor heat load," Journal of Turbomachinery, vol. 119, no. 3, pp. 544-553, 1997.

[21] R. P. Dring, M. F. Blair, H. D. Joslyn, G. D. Power, and J. M. Verdon, "The effects of inlet turbulence and rotor/stator interactions on the aerodynamics and heat transfer of a largescale rotating turbine model," Final Report NASA-CR-4079, United Technologies Research Center, East Hartford, Conn, USA, 1987.

[22] O. P. Sharma, G. M. Stetson, W. A. Daniels, E. M. Greitzer, M. F. Blair, and R. P. Dring, "Impact of periodic unsteadiness on performance and heat load in axial flow turbomachines," Final Report NASA-CR-202319, NASA Lewis Research Center, Cleveland, Ohio, USA, 1997.

[23] W. J. Whitney, R. G. Stabe, and T. P. Moffitt, "Description of the warm core turbine facility recently installed at NASA Lewis Research Center," Final Report NASA-TM-81562, NASA Lewis Research Center, Cleveland, Ohio, USA, 1980.

[24] J. R. Schwab, R. G. Stabe, and W. J. Whitney, "Analytical and experimental study of flow through an axial turbine stage with a nonuniform inlet radial temperature profile," Final Report NASA-TM-83431, NASA Lewis Research Center, Cleveland, Ohio, USA, 1983.

[25] R. G. Stabe, W. J. Whitney, and T. P. Moffitt, "Performance of a high-work low aspect ratio turbine tested with a realistic inlet radial temperature profile," Final Report AIAA-84-1161, NASA Lewis Research Center, Cleveland, Ohio, USA, 1984.

[26] G. R. Guenette, "A fully scaled short duration turbine experiment," Sc.D. thesis, MIT, Cambridge, Mass, USA, 1985.

[27] D. D. Sujudi, "An experimental investigation of the effects of inlet circumferential temperature distortion on the aerodynamic performance of a single stage turbine," Master's thesis, MIT, Cambridge, Mass, USA, 1994.

[28] T. Shang, "Influence of inlet temperature distortion on turbine heat transfer," Philosophy Doctor's thesis, MIT, Cambridge, Mass, USA, 1995.

[29] T. Shang, G. R. Guenette, A. H. Epstein, and A. P. Saxer, "The influence of inlet temperature distortion on rotor heat transfer in a transonic turbine," AIAA Paper 95-3042, AIAA, San Diego, Calif, USA, 1995.

[30] D. J. Dorney, R. L. Davis, and O. R. Sharma, "Two-dimensional inlet temperature profile attenuation in a turbine stage," ASME Paper 91-GT-406, ASME, Orlando, Fla, USA, 1991.

[31] S. R. Mathur, N. K. Madavan, and R. G. Rjagopala, "A solution-adaptive hybrid-grid method for the unsteady analysis of turbomachinery," AIAA Paper 93-3015, AIAA, Orlando, Fla, USA, 1993.

[32] R. Takahashi and R. H. Ni, "Unsteady Euler analysis of the redistribution of an inlet temperature distortion in a turbine," AIAA Paper 90-2262, AIAA, Orlando, Fla, USA, 1990.

[33] R. Takahashi and R. H. Ni, "Unsteady hot streak simulation through a 1-1/2 stage turbine," AIAA Paper 91-3382, AIAA, Sacramento, Calif, USA, 1991.

[34] B. Krouthen and M. B. Giles, "Numerical investigation of hot streaks in turbines," AIAA Paper 88-3015, AIAA, Boston, Mass, USA, 1988.

[35] S. P. Harasgama, "Combustor exit temperature distortion effects on heat transfer and aerodynamics within a rotating turbine blade passage," ASME Paper 90-GT-174, ASME, Brussels, Belgium, 1990.

[36] B. Weigand and S. P. Harasgama, "Computations of a film cooled turbine rotor blade with non-uniform inlet temperature distribution using a three-dimensional viscous procedure," ASME Paper 94-GT-15, ASME, The Hague, The Netherlands, 1994.

[37] K. R. Kirtley, M. L. Celestina, and J. J. Adamczyk, "The effect of unsteadiness on the time-mean thermal loads in a turbine stage," SAE Paper 931375, SAE, Dayton, Ohio, USA, 1993.

[38] A. P. Saxer and M. B. Giles, "Inlet radial temperature redistribution in a transonic turbine stage," AIAA Paper 90-1543, AIAA, Orlando, Fla, USA, 1990.

[39] A. P. Saxer and H. M. Felici, "Numerical analysis of 3-D unsteady hot streak migration and shock interaction in a turbine stage," ASME Paper 94-GT-76, ASME, Hague, The Netherlands, 1994.

[40] D. J. Dorney and J. R. Schwab, "Unsteady numerical simulations of radial temperature profile redistribution in a singlestage turbine," ASME Paper 95-GT-178, ASME, Houston, Tex, USA, 1995.

[41] Fine Turbo User Manual 6-2-9, NUMECA International, 2005. 
[42] A. Arnone and R. Pacciani, "Rotor-stator interaction analysis using the Navier-Stokes equations and a multigrid method," Journal of Turbomachinery, vol. 118, no. 4, pp. 679-689, 1996.

[43] A. Jameson, "Time dependent calculations using multigrid with applications to unsteady flows past airfoils and wings," AIAA Paper 91-1596, AIAA, Honolulu, Hawii, USA, 1991.

[44] P. Spalart and S. Allmaras, "A one-equation turbulence model for aerodynamic flows," AIAA Paper 92-0439, AIAA, Reno, Nev, USA, 1992.

[45] H. S. Wang, J. Z. Xu, X. L. Zhao, and Q. J. Zhao, "Numerical investigation on performance of vaneless counter-rotating turbine," ISABE Paper 2005-1159, ISABE, Munich, Germany, 2005.

[46] Q. J. Zhao, H. S. Wang, X. L. Zhao, and J. Z. Xu, "Threedimensional numerical simulation of $1+1 / 2$ counter-rotating turbine," Tech. Rep. CSET-2004-042012, Chinese Society of Engineering Thermophysics, 2004.

[47] D. J. Dorney, D. L. Sondak, and P. G. A. Cizmas, "Effects of hot streak/airfoil ratio in a high-subsonic single-stage turbine," AIAA Paper 99-2384, AIAA, Los Angeles, Calif, USA, 1999.

[48] Q. J. Zhao, H. S. Wang, X. L. Zhao, and J. Z. Xu, "Numerical investigation of 3-D unsteady hot streak migration in a vaneless counter-rotating turbine," Tech. Rep. CSET-2005-052003, Chinese Society of Engineering Thermophysics, 2005.

[49] S. L. Dixon, Fluid Mechanics, Thermodynamics of Turbomachinery, Pergamon Press, New York, NY, USA, 3rd edition, 1978. 

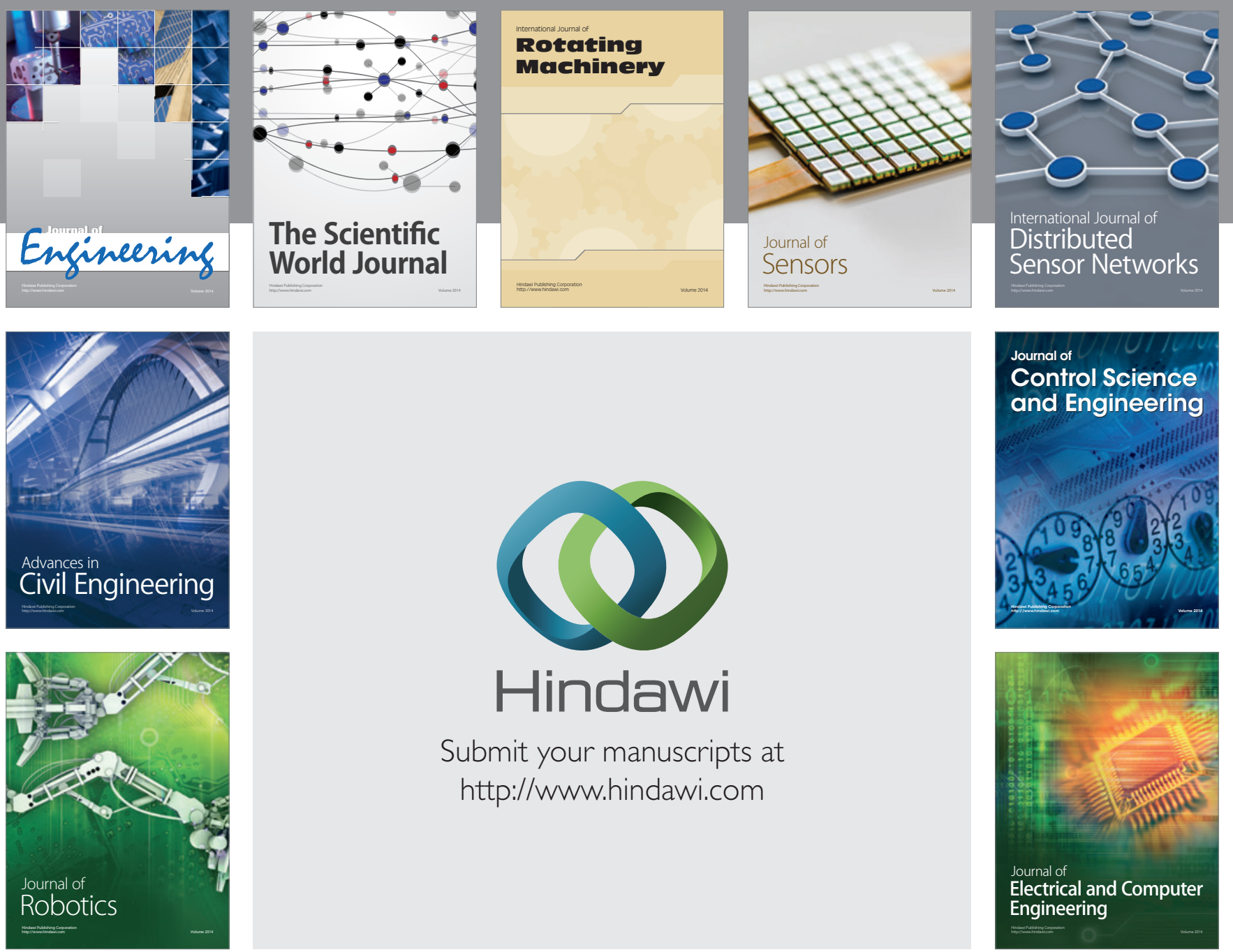

Submit your manuscripts at

http://www.hindawi.com
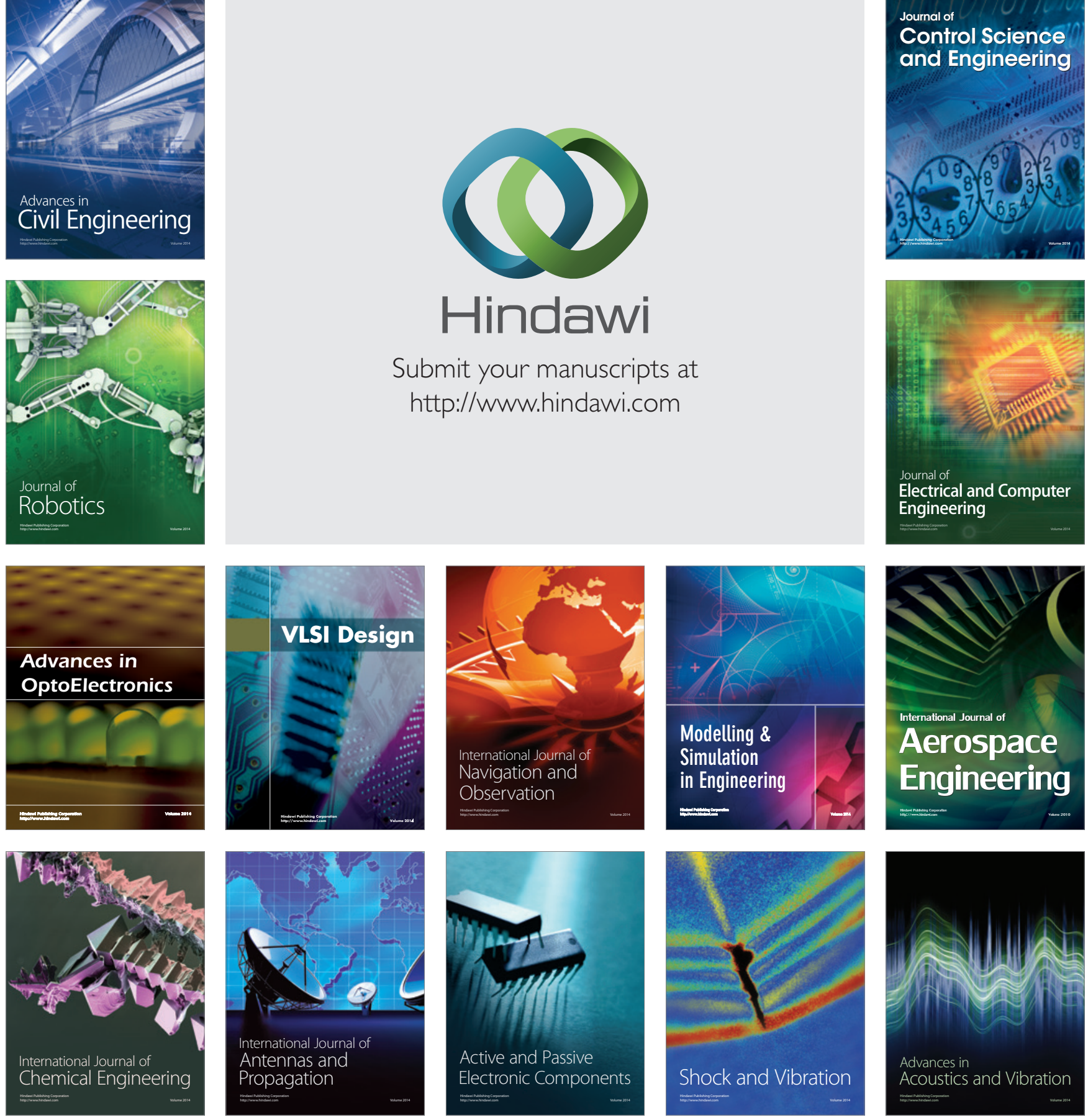